\title{
Extended Aging and Marbling Class Effects on Color Stability of Beef Longissimus lumborum, Gluteus medius, and Biceps femoris Steaks
}

\author{
D. Andy King*, Steven D. Shackelford, Robert A. Cushman, and Tommy L. Wheeler \\ USDA-ARS, Roman L. Hruska U.S. Meat Animal Research Center, Clay Center, NE 68933-0166, USA \\ *Corresponding author. Email: andy.king@usda.gov (D. Andy King)
}

\begin{abstract}
Postmortem aging improves palatability of various muscles, especially those from lower quality grades. This study evaluated postmortem aging and marbling class effects on the color stability of longissimus lumborum, gluteus medius, and biceps femoris steaks. Carcasses were selected at grading to have Lower Small ( $\mathrm{Small}{ }^{00}$ to $\left.\mathrm{Small}{ }^{50} ; n=50\right)$ or Upper Slight (Slight ${ }^{50}$ to Slight ${ }^{90} ; n=50$ ) marbling scores. Strip loin and top sirloin subprimals from each carcass side were assigned to aging treatments $(14,21,28$, or $35 \mathrm{~d})$ in an incomplete block arrangement. After aging, subprimals were cut into longissimus lumborum, gluteus medius, and biceps femoris steaks, respectively. Steaks were placed in a simulated retail display for $11 \mathrm{~d}$. Changes in redness ( $a^{*}$ and hue angle) were much slower and less extensive $(P<0.001)$ in $l o n g-$ issimus lumborum steaks than in gluteus medius steaks, which had slightly slower and less extensive $(P<0.01)$ redness changes than biceps femoris. Increasing aging time increased $(P<0.001)$ the rate and extent of overall color change $(\Delta \mathrm{E})$ during simulated retail display. Steaks from Lower Small carcasses had higher $(P<0.01) L^{*}$ values than steaks from Upper Slight carcasses at 14, 28, and $35 \mathrm{~d}$ postmortem. In steaks from Upper Slight carcasses, $L^{*}$ values were lower $(P<0.01)$ in steaks aged for $28 \mathrm{~d}$ compared to other aging times. In steaks from Lower Small carcasses, $L^{*}$ values were highest $(P<0.001)$ when aged for $14 \mathrm{~d}$. Increased aging time generally decreased $(P<0.05) a^{*}, b^{*}$, and chroma values. However, within each aging time, only $b^{*}$ values of steaks aged for $35 \mathrm{~d}$ differed $(P=0.01)$ with regard to marbling class. Results indicate that increasing aging time decreased color life of beef muscles, and that marbling class had minimal impact on lean color stability.
\end{abstract}

Key words: aging, beef, color stability, marbling, muscles

Meat and Muscle Biology 5(1): 21, 1-14 (2021) doi:10.22175/mmb.11139

Submitted 15 April $2020 \quad$ Accepted 31 August 2020

\section{Introduction}

Meeting consumers' expectations for palatability continues to be a challenge for foodservice and retail operators. Insufficient tenderness has been identified as a primary challenge in meeting these expectations (Boleman et al., 1997; Neely et al., 1998; Miller et al., 2001; Shackelford et al., 2001). Thus, strategies for ensuring the tenderness of meat products continue to be heavily utilized. Of these strategies, postmortem aging is among the simplest and most effective available, and extended aging times are widely used (Martinez et al., 2017), particularly in premium product lines. Previous research from our laboratory has demonstrated degradation of cytoskeletal proteins resulting in tenderization through $42 \mathrm{~d}$ of refrigerated storage (King et al., 2009a, 2009b, 2009c). Gruber et al. (2006) indicated that aging times were muscle dependent and that muscles from U.S. Select carcasses required longer aging times to reach ultimate tenderness levels than muscles from the Upper $2 / 3$ of the U.S. Choice grade. However, U.S. Select (Slight marbling) carcasses are generally discounted relative to U.S. Choice (Small, Modest, and Moderate marbling) carcasses, and aging is commonly used to improve cuts from U.S. Select carcasses. 
Despite such emphasis on aging as it pertains to tenderness, comparatively little effort has been directed to the effects of aging on other important meat quality attributes, particularly for longer aging times. Beef retail color stability is a quality attribute of importance influencing consumer purchasing decisions. Colle et al. (2015) reported that increasing aging time of gluteus medius and longissimus lumborum muscles up to $63 \mathrm{~d}$ postmortem increased consumer ratings. However, in that experiment, increased aging decreased color stability of both muscles.

Increased postmortem aging has been reported to influence beef color (Lee et al., 2008a, 2008b; Mancini and Ramanathan, 2014) and reduce lean color stability (Mancini and Ramanathan, 2014; English et al., 2016; Mitacek et al., 2019). Moreover, postmortem aging has been reported to affect the biochemical processes determining lean color stability (Ledward, 1985; Feldhusen et al., 1995; Tang et al., 2005a, 2005b). Oxygen consumption and metmyoglobin reducing activity play key roles in determining lean color and color stability (Tang et al., 2005a, 2005b; Ramanathan et al., 2013). Mancini and Ramanathan (2014) reported reductions in mitochondrial oxygen consumption and metmyoglobin reducing ability with increased postmortem aging time, which was associated with greater bloom development, coupled with decreased color stability.

Muscles differ with regard to lean color stability (McKenna et al., 2005; King et al., 2011). Muscles within a carcass differ in metabolic characteristics. Muscles with greater lean color stability have been reported to have greater abundance of glycolytic enzymes and proteins that act as antioxidants and chaperones (Joseph et al., 2012; Nair et al., 2018). Muscle differences in color stability are associated with the relative capacity of each muscle for oxygen consumption and metmyoglobin reduction (McKenna et al., 2005).

Muscles differ in metabolic characteristics that are impacted by postmortem aging. It is not clear how these changes interact with even small differences in marbling level to impact lean color stability. The present experiment was conducted to examine the effects of extended postmortem aging on beef lean color stability in 3 muscles from carcasses representing 2 classes of marbling scores.

\section{Materials and Methods}

Carcasses used in this experiment were selected, postmortem, from a commercial packing facility. Thus, animal care and use approval was not obtained for this experiment.

\section{Sample selection and handling}

Carcasses $(N=100)$ were selected from a commercial packing facility, approximately $36 \mathrm{~h}$ postmortem, as they were presented for grading. Using the output of the US Meat Animal Research Center beef image analysis grading system (VBG 2000, Oranenberg, Germany; Shackelford et al., 2003), carcasses were selected to have marbling scores that were either between Slight ${ }^{50}$ and Slight ${ }^{90}$ (Upper Slight; $n=50$ ) or between Small ${ }^{00}$ and Small ${ }^{40}$ (Lower Small; $n=50$ ). Thus, carcasses included in the present experiment represented the U.S. Select and U.S. Choice grades. Carcasses were selected on 3 production days ( 2 to 3 wk apart, $n=40,40$, and 20, respectively), and although production lot was not considered during carcass selection, this information was recorded for each carcass. The beef loin strip loin (similar to Institutional Meat Purchase Specifications \#180 [USDA, 2014]) and beef loin top sirloin butt (similar to Institutional Meat Purchase Specifications \#184 [USDA, 2014]) were collected from both sides of each carcass assigned to postmortem aging times of $14,21,28$, or $35 \mathrm{~d}$ in an incomplete block arrangement so that each combination of aging times occurred within a carcass an equal number of times. Moreover, carcass sides were assigned to aging times so that, within each aging time comparison, the number of left and right sides assigned to each aging time were as balanced as possible. For example, 17 carcasses had cuts assigned to both the 14- and 28-d aging times, of which 8 carcasses had cuts from the left side assigned to the 14-d aging period. After fabrication, each subprimal was sorted into its respective aging time, vacuum packaged $\left(<10 \mathrm{~mL} / \mathrm{M}^{2} / 24 \mathrm{~h}\right.$ at $23^{\circ} \mathrm{C}, 0 \%$ relative humidity; Cryovac, Duncan, SC), boxed, palletized, and shipped under refrigeration $\left(-2^{\circ} \mathrm{C}\right)$ to the US Meat Animal Research Center abattoir, where they were aged $\left(-1^{\circ} \mathrm{C}\right)$ for the prescribed time.

After aging, subprimals were unpackaged, and the top sirloin butt was separated into the gluteus medius (with the gluteus accessorius removed) and the proximal portion of the biceps femoris (sirloin cap). A 1.27-cmthick slice and a 2.54-cm-thick steak were removed from the anterior aspect of the gluteus medius for use for measurement of $\mathrm{pH}$ and myoglobin concentration, and simulated retail display, respectively. A 2.54-cm-thick steak was removed from the most posterior aspect of each biceps femoris muscle and used for simulated retail display. A $1.27-\mathrm{cm}$-thick steak and two $2.54-\mathrm{cm}$-thick 
steaks were removed from the anterior portion of each longissimus lumborum for use in myoglobin and $\mathrm{pH}$ determination, simulated retail display, and determination of oxygen consumption and nitric oxide metmyoglobin reducing ability, respectively. Steaks designated for myoglobin concentration and muscle $\mathrm{pH}$ were vacuum packaged and frozen until analysis.

\section{Simulated retail display}

Steaks were placed on polystyrene trays with soaker pads and overwrapped with oxygen-permeable polyvinylchloride film (Stretchable meat film 55003815; Prime Source, St. Louis, MO; oxygen transmission rate $=1.4 \mathrm{~mL} / \mathrm{cm}^{2} / 24 \mathrm{~h}$ at $23^{\circ} \mathrm{C}$ ). Steaks were placed under continuous fluorescent lighting (color temperature $=3,500 \mathrm{~K}$; color rendering index $=86 ; 32$ Watt; T8 Ecolux bulb [model number F32T8/SPX35 GE, GE Lighting, Cleveland, $\mathrm{OH}]$ ), and light intensity at the meat surface was approximately $2,000 \mathrm{~lx}$. Display was conducted in a refrigerated room $\left(1{ }^{\circ} \mathrm{C}\right)$, and no temperature fluctuations associated with defrost cycles were encountered.

Steaks cut after aging were bloomed for at least $2 \mathrm{~h}$ after being packaged before color measurements were taken. Instrumental color readings were taken on each steak on day $0,1,4,7$, and 11 using a HunterLab Miniscan XE Plus colorimeter (HunterLab, Reston, VA) with a 25-mm port. The colorimeter was set to collect spectral data with Illuminant A and a $10^{\circ}$ observer. Commission Internationale de $1^{\prime}$ Eclairage ("International Commission on Illumination") $L^{*}$ (lightness), $a^{*}$ (redness), and $b^{*}$ (yellowness) color-space values were reported as the average of duplicate readings taken on each steak. Chroma (color intensity; also known as saturation index) was calculated as $\left[\left(a^{* 2}+b^{* 2}\right)^{0.5}\right]$. Hue angle (redness) was calculated as [Arctangent $\left.\left(b^{*} / a^{*}\right) \times 180 / 3.142\right]$. Overall color change $(\Delta \mathrm{E})$ was calculated as $\left[\left(\Delta L^{* 2}+\Delta a^{* 2}+\Delta b^{* 2}\right)^{0.5}\right]$, where $\Delta L^{*}$, $\Delta a^{*}$, and $\Delta b^{*}$ are the difference between day 0 and day $1,4,7$, and 11 values for $L^{*}, a^{*}$, and $b^{*}$, respectively. Additionally, spectral data were used to calculate $\mathrm{K} / \mathrm{S}_{572} / \mathrm{K} / \mathrm{S}_{525}$ ratios to estimate accumulation of metmyoglobin as described by the American Meat Science Association (2012).

\section{pH and myoglobin concentration}

Myoglobin concentration and $\mathrm{pH}$ were measured on the $1.27-\mathrm{cm}$ steaks removed from the most anterior portion of the longissimus lumborum and gluteus medius muscles. Because the small size of the biceps femoris (sirloin cap) limited the number of steaks available, these traits were determined on the simulated retail display steak after the display period was completed. Previously frozen steaks were thawed enough to be diced, but not enough for purge to be released from the steak. In each case, steaks were trimmed free of external fat and epimysium, diced, and pulverized in liquid nitrogen to produce a homogenous powder. Muscle $\mathrm{pH}$ was determined as prescribed by Bendall (1973). Duplicate 2.5-g powdered samples were homogenized in 10 volumes of a $5 \mathrm{mM}$ iodoacetate, $150 \mathrm{~m} M \mathrm{KCl}$ solution $(\mathrm{pH}=7.0)$. Homogenates were held for a minimum of $1 \mathrm{~h}$ at room temperature and mixed via vortexing, and $\mathrm{pH}$ was measured using a semi-micro combination electrode (Corning, Inc., Corning, NY) attached to a Corning $125 \mathrm{pH}$ meter.

Myoglobin was extracted and quantified following the method described by Warris (1979) as modified by Hunt et al. (1999). Briefly, duplicate 2.5-g powdered samples were homogenized in 10 volumes of $40 \mathrm{mM}$ potassium phosphate buffer $(\mathrm{pH}=6.8)$. Homogenates were held, on ice, for $1 \mathrm{~h}$ to allow complete pigment extraction before centrifugation $(15,000 \times \mathrm{g})$ for $30 \mathrm{~min}$ at $4^{\circ} \mathrm{C}$. Supernatant $(1.5 \mathrm{~mL})$ was syringe filtered (Nalgene $0.45 \mu \mathrm{m}$, surfactant-free cellulose acetate membrane; Thermo Fisher Scientific, Rochester, NY) into a 4-mL cuvette with $1 \mathrm{~mL}$ of $40 \mathrm{mM}$ phosphate buffer and $0.5 \mathrm{~mL}$ of sodium hydrosulfite $(10 \mathrm{mg} / \mathrm{mL})$. Absorbance spectra (400 to $700 \mathrm{~nm}$ ) was scanned on each sample using a DU 640 spectrophotometer (Beckman Coulter, Inc, Fullerton, CA). Once samples were verified to be in the reduced state (absorbance peak within $2 \mathrm{~nm}$ of 433), extracted pigment concentration was calculated using the absorbance at $433 \mathrm{~nm}$, a molar extinction coefficient of $114,000 \mathrm{M}^{-1} \mathrm{~cm}^{-1}$, the molecular weight of myoglobin $(16,800)$, and the appropriate dilution factor.

\section{Oxygen consumption}

From each longissimus lumborum muscle, the steak immediately posterior to the simulated retail display steak was used to determine oxygen consumption and nitric oxide metmyoglobin reducing ability. After cutting, these steaks were placed on a plastic tray, covered with the same film used for simulated retail packages, and allowed to bloom in the same refrigeration and lighting conditions used for simulated retail display for at least $2 \mathrm{~h}$. From the center portion of each steak, a cube $(2.54 \mathrm{~cm} \times 2.54 \mathrm{~cm} \times$ steak thickness $)$ was cut that was free of visible connective tissue and large marbling flecks. The cube was divided into top and bottom halves along the original steak thickness 
dimension, exposing the interior of the steak that had never been exposed to air or light. The top surface of the bottom half of the cube removed from each steak, which had previously been the interior of the steak, was used for measuring oxygen consumption. The newly exposed portion of the steak was oxygenated for $30 \mathrm{~min}$ at $1^{\circ} \mathrm{C}$. The sample was vacuum packaged and scanned immediately with a HunterLab Miniscan XE Plus colorimeter with the settings previously described, with the modification that the colorimeter was calibrated through the oxygen-impermeable film of a vacuum bag. The vacuum package was incubated for $30 \mathrm{~min}$ in a $30^{\circ} \mathrm{C}$ water bath and scanned with the colorimeter to collect spectral data. The proportion of surface oxymyoglobin was calculated on the oxygenated and deoxygenated samples as described by the American Meat Science Association (2012). Standards for 100\% deoxymyoglobin and oxymyoglobin were created using the methods described by Mancini et al. (2003). Oxygen consumption was reported as the percentage of oxymyoglobin prior to incubation minus the percentage of oxymyoglobin after incubation.

\section{Nitric oxide metmyoglobin reducing ability}

Metmyoglobin reducing ability was measured on the top half of the cube removed from the steak on the surface that had been previously exposed to light in a manner as described by Sammel et al. (2002). The sample was oxidized in $50 \mathrm{~mL}$ of a $0.3 \%$ sodium nitrite solution for $20 \mathrm{~min}$ at approximately $20^{\circ} \mathrm{C}$. The sample then was removed from the solution, blotted, and vacuum packaged. Immediately following packaging, the sample was scanned with the HunterLab Miniscan colorimeter with previously described settings. The sample was allowed to reduce in a $30^{\circ} \mathrm{C}$ water bath for $2 \mathrm{~h}$, when the sample was rescanned. Surface metmyoglobin was quantified using the equations defined by the American Meat Science Association (2012). The proportion of surface metmyoglobin initially recorded immediately after oxidation with nitrite was reported as initial metmyoglobin formation (IMF). Metmyoglobin reducing activity was reported as the absolute difference in surface metmyoglobin between the initial (oxidized) readings and the final (reduced) readings.

\section{Statistical analysis}

These data were analyzed as a split plot using the PROC GLIMMIX procedure of SAS version 9.4 (SAS Institute Inc., Cary, NC). The whole plot experimental unit was carcass with treatments of marbling class and muscle. The subplot experimental unit was muscle with the treatment of aging time. The model analyzing simulated retail display data tested the fixed effects of muscle, aging time, and marbling class. Data were analyzed as repeated measures with a spatial power covariance structure. Day of display and its square were fit as covariates. The model also tested all possible interactions among fixed effects and covariates. Nonsignificant $(P>0.05)$ covariate and covariate interaction terms were removed from the model; thus, the simplest regression equations describing changes in color traits during simulated retail display were determined using contrast statements. For effects involving day of display, linear orthogonal contrasts were used to determine whether the intercepts and/ or $\beta$-coefficients associated with color change of steaks from differing treatments differed from one another. For effects not involving day of display, least-squares means were separated using the "DIFF" and "LINES" options.

Myoglobin, mitochondrial abundance, and $\mathrm{pH}$ data were analyzed with a similar model to the one described earlier with the exception that day of display was not included. Oxygen consumption and nitric oxide metmyoglobin reducing activity data were analyzed using a model similar to those earlier but excluding both day of display and muscle. Pearson correlation coefficients were obtained for biochemical traits and color attributes on day 0 and 11 of display longissimus lumborum steaks using the PROC CORR procedure of SAS. Correlations were also calculated among residuals for these traits after aging effects had been removed using a mixed model with the fixed effect of aging time and random effects of selection day and carcass (marbling class). A significance level of 0.05 was used for all judgments of statistical significance.

\section{Results}

\section{Muscle $\times$ display day interaction}

The muscles examined in the present experiment were selected for this experiment because of their importance to the retail sector. Moreover, in our previous comparisons of 14 beef muscles (King et al., 2011), these muscles were the most stable (longissimus lumborum), the most labile (biceps femoris, sirloin cap), and intermediate (gluteus medius) during simulated retail display. Muscle interacted with day of display for all the color attributes evaluated. Trends for change in lean color attributes of each of these muscles during simulated retail display are presented in Figure 1. At the onset of retail display, gluteus medius steaks had the greatest $(P<$ $0.001)$ and biceps femoris had the lowest $(P<0.001)$ 

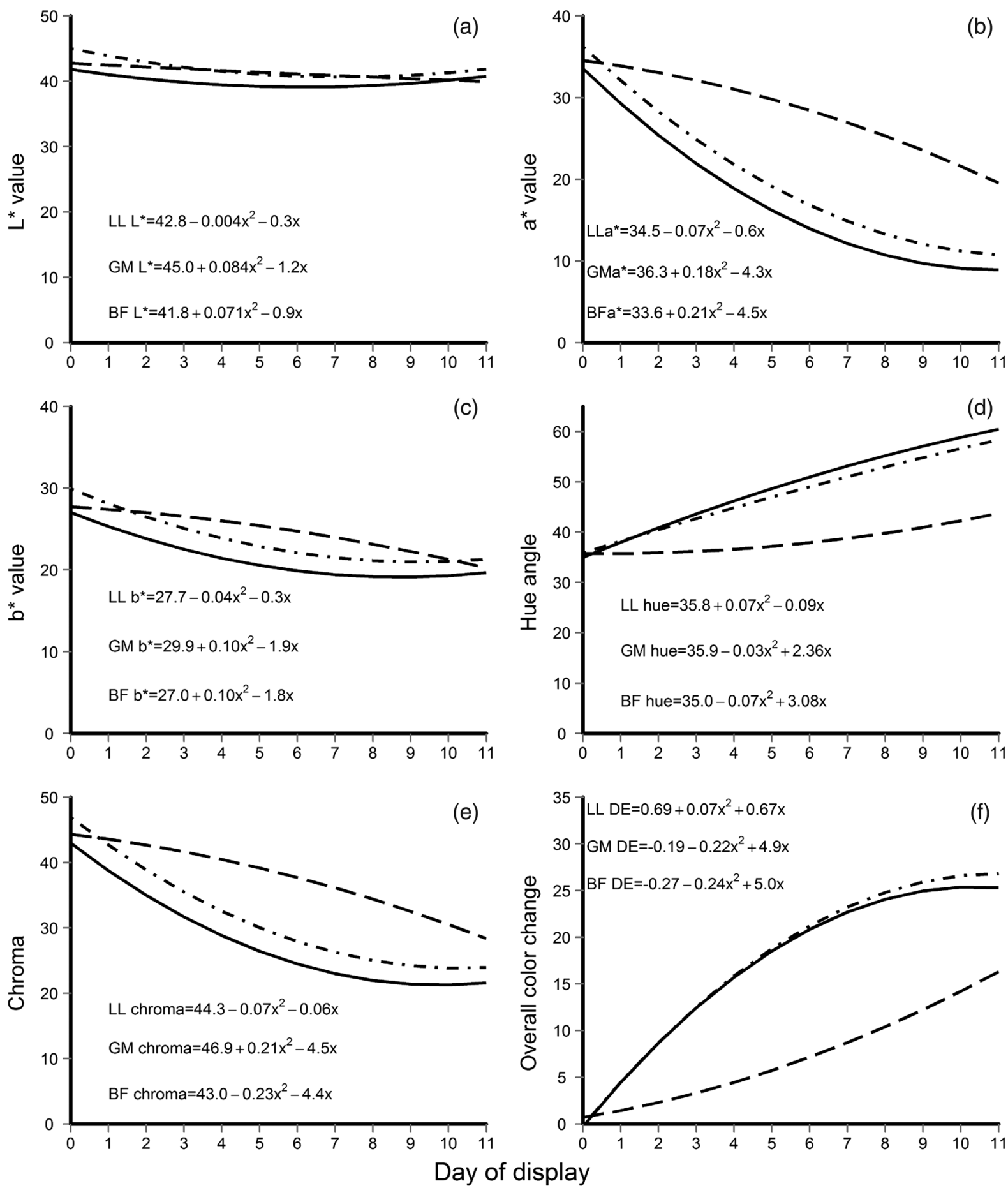

Day of display

$\mathrm{BF} \cdot-\cdot \mathrm{GM}--\mathrm{LL}$

Figure 1. Regression trends for changes in lean color attributes of longissimus lumborum, gluteus medius, and biceps femoris steaks during simulated retail display. BF, biceps femoris; DE, $\Delta \mathrm{E}$, overall color change; GM, gluteus medius; LL, longissimus lumborum.

$L^{*}$ values, with longissimus lumborum steaks having intermediate $L^{*}$ values (Figure 1A) although these differences were small in magnitude. The linear and quadratic terms that described the change in $L^{*}$ values during display differed $(P<0.05)$ among the 3 muscles.
Day $0 a^{*}$ values were lowest $(P<0.001)$ for biceps femoris steaks, greatest $(P<0.001)$ in gluteus medius, and intermediate in longissimus lumborum steaks (Figure 1B). Redness ( $a^{*}$ values) decreased in all 3 muscles during simulated retail display. In longissimus 
lumborum steaks, $a^{*}$ values decreased slowly early in the display period and more rapidly later in the display period. Conversely, $a^{*}$ values decreased rapidly in the display period and then more slowly in the latter portion of the display period in gluteus medius and biceps femoris steaks. The slower $(P<0.001)$ losses of redness in longissimus lumborum steaks compared to gluteus medius and biceps femoris steaks were also reflected in hue angle values (Figure 1D). Although the intercept, linear, and quadratic $\beta$-coefficients describing changes in hue angle differed $(P<0.05)$ between gluteus medius and biceps femoris steaks, the resulting trend lines were very similar.

Changes in $b^{*}$ and chroma values followed similar trends (Figure 1C and $1 \mathrm{E}$ ). As time in display increased, the values of these variables decreased, though the trend associated with longissimus lumborum steaks differed from the trends associated with gluteus medius and biceps femoris, which were similar. In longissimus lumborum steaks, changes in these attributes occurred slowly early in the display period and then more rapidly as time in display increased. Conversely, in gluteus medius and biceps femoris steaks, change in these variables was more rapid early in the display period and slowed as time in display increased. Initial values for $b^{*}$ and chroma were higher $(P<0.001)$ for biceps femoris than for gluteus medius steaks, but the $\beta$-coefficients for the linear and quadratic terms describing their change were similar $(P=0.06)$ for the 2 muscles. For both gluteus medius and biceps femoris steaks, overall color change occurred rapidly in the early portion of display followed by a plateau after day 8 of display (Figure 1F). In contrast, overall color change of longissimus lumborum occurred more slowly in the early portion of the display period and then at an increasing rate as the display period progressed.

\section{Aging time $\times$ display day interaction}

Aging time also interacted with day of display to affect all the color attributes evaluated in this experiment (Figure 2). The initial $L^{*}$ values were higher $(P<0.02)$ in steaks from subprimals aged for 14 or $35 \mathrm{~d}$ than in steaks from 21- or 28-d aging (Figure 2A). However, changes in $L^{*}$ values during display did not differ $(P>0.05)$ among the aging times evaluated in this experiment. Redness $\left(a^{*}\right)$ did not differ $(P>0.05)$ among aging times on day 0 of display (Figure $2 \mathrm{~B}$ ). Increasing aging time increased $(P<0.05)$ the rate of decline in $a^{*}$ values during simulated retail display. Steaks from $35-\mathrm{d}$ aging had the greatest $(P<0.001)$ rate of decline in $a^{*}$ values, whereas steaks from 14-d aging had the lowest $(P<0.001)$.

On day 0 of display, steaks from 14-d aging had the highest $(P<0.001) b^{*}$ values (Figure $\left.2 C\right)$. Steaks from 35-d aging had a more rapid $(P<0.001)$ decline in $b^{*}$ values than steaks from all shorter aging times. Initial color intensity (chroma) did not differ $(P>0.07)$ across aging times (Figure 2E). The decline in chroma during display was most rapid $(P<0.001)$ in steaks from 35-d aging and slowest $(P=0.01)$ in steaks from 14-d aging.

On day 0 of display, steaks from 14-d aging had the highest $(P<0.02)$ hue angle values compared to steaks from longer aging periods (Figure 2D). Although statistical differences in the parameters describing the changes in hue angle during display across aging times were detected $(P<0.05)$, the trends in hue angle associated with the aging times evaluated in the present study were likely not practically important.

Overall color change $(\Delta \mathrm{E})$ increased rapidly during the early portion of the display period (Figure $2 \mathrm{~F}$ ). As the time in display increased, the rate of overall color change decreased. The rate of color change was slowest $(P<$ $0.001)$ in steaks from 14-d aging, greatest $(P<0.001)$ for 35-d aging, and intermediate in steaks from 21- and 28-d postmortem aging.

\section{Muscle, aging time, and marbling class main effects and their interactions}

Hue angle values were higher $(P<0.001)$ for biceps femoris (sirloin cap portion) steaks than those for longissimus lumborum steaks, which were much higher $(P<$ $0.001)$ than those for gluteus medius steaks (Table 1). Furthermore, hue angle values were higher $(P<0.03)$ for steaks from 14-d aging than for those aged for any other time except $28 \mathrm{~d}$. Hue angle values were lowest $(P<0.03)$ in steaks from 21 -d postmortem aging.

A muscle $\times$ aging time interaction affected $L^{*}, b^{*}$, and overall color change $(\Delta \mathrm{E})$ values. Regardless of aging time, lightness $\left(L^{*}\right)$ was greatest $(P<0.05)$ in gluteus medius steaks and lowest $(P<0.05)$ in biceps femoris steaks. In longissimus lumborum steaks, $L^{*}$ values were lower $(P<0.03)$ in steaks from 35 -d aging than those from 14- or 28-d aging. For gluteus medius steaks, $L^{*}$ values were highest $(P<0.001)$ in steaks from 14 -d aging and lowest $(P<0.01)$ in steaks from 21- or 28-d postmortem aging. Biceps femoris steaks from 21 - or 28 -d aging had lower $(P<0.01) L^{*}$ values than biceps femoris steaks from 14- or 35-day aging times. Yellowness $\left(b^{*}\right)$ values were greater $(P<$ 0.05 ) for longissimus lumborum and gluteus medius 

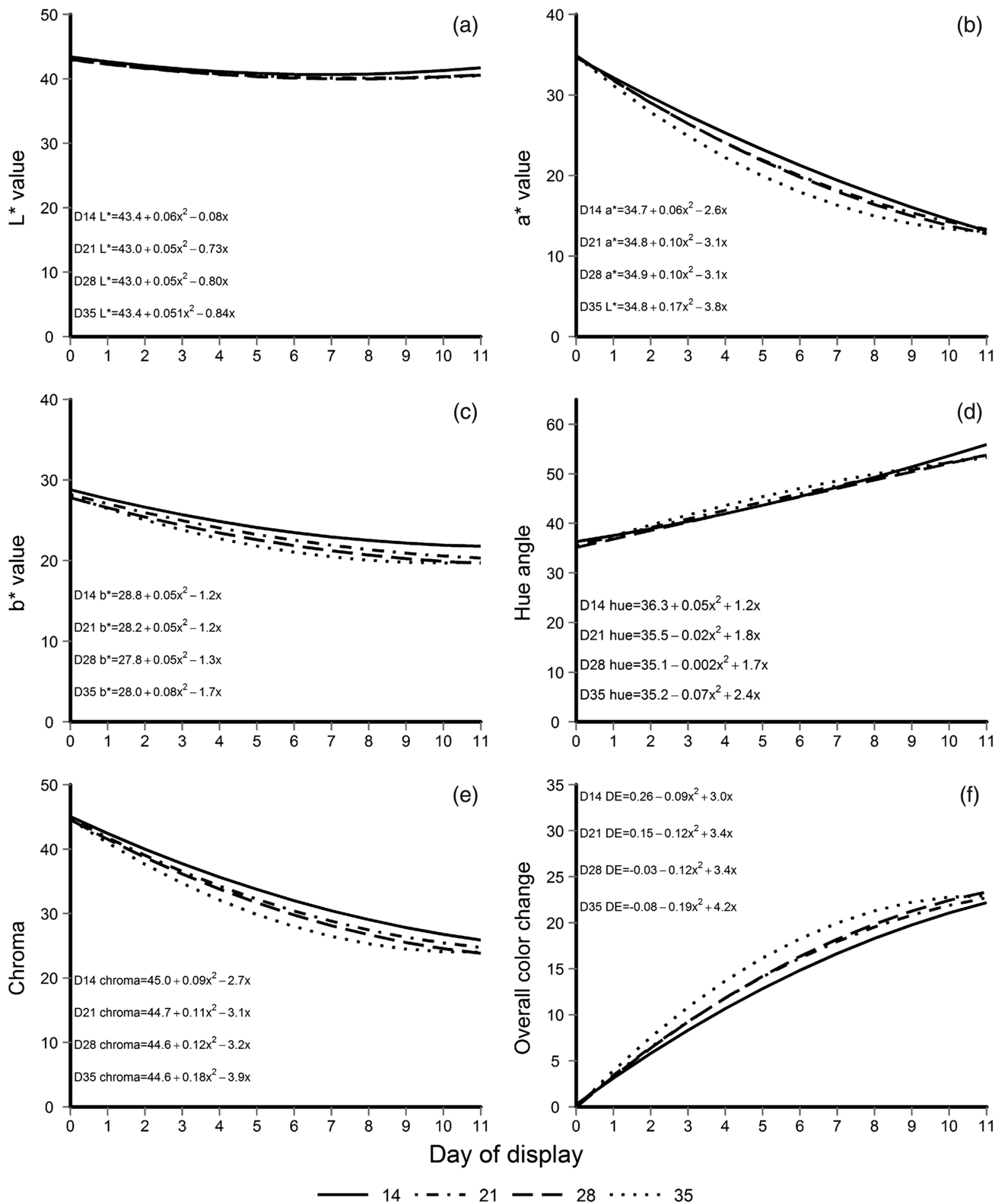

Figure 2. Regression trends for changes in lean color attributes of steaks aged for $14,21,28$, or $35 \mathrm{~d}$ postmortem during simulated retail display. DE, $\Delta \mathrm{E}$, overall color change.

steaks than for biceps femoris steaks regardless of aging time. When aged for $28 \mathrm{~d}$, longissimus lumborum steaks had higher $(P=0.01) b^{*}$ values than gluteus medius steaks; however, steaks from these 2 muscles had similar $b^{*}$ values within each of the other aging times. Each increase in aging time resulted in decreased
$(P<0.002) b^{*}$ values in longissimus lumborum. Similarly, in gluteus medius and biceps femoris steaks, $b^{*}$ values decreased $(P<0.05)$ when aging time was increased, but each aging increment was not always significant. Overall color change $(\Delta \mathrm{E})$ was much less extensive $(P<0.05)$ in longissimus lumborum steaks 
Table 1. Least-squares means for color attributes for muscle, aging time, and marbling class effects and their interactions during simulated retail display

\begin{tabular}{|c|c|c|c|c|c|c|c|}
\hline Main effects and interactions & & $L^{*}$ & $a^{*}$ & $b^{*}$ & Hue angle & Chroma & $\Delta \mathrm{E}$ \\
\hline \multicolumn{8}{|l|}{ Muscle } \\
\hline \multicolumn{2}{|l|}{ Longissimus lumborum } & 41.5 & 23.2 & 24.9 & $45.7^{\mathrm{b}}$ & 34.5 & 13.6 \\
\hline \multicolumn{2}{|l|}{ Gluteus medius } & 42.6 & 29.2 & 25.1 & $38.1^{\mathrm{c}}$ & 38.6 & 14.0 \\
\hline \multicolumn{2}{|l|}{ Biceps femoris } & 40.4 & 20.6 & 22.6 & $46.6^{\mathrm{a}}$ & 31.0 & 6.3 \\
\hline \multicolumn{2}{|l|}{ SEM } & 0.2 & 0.2 & 0.1 & 0.2 & 0.2 & 0.2 \\
\hline \multicolumn{2}{|l|}{$P>\mathrm{F}$} & $<0.001$ & $<0.001$ & $<0.001$ & $<0.001$ & $<0.001$ & $<0.001$ \\
\hline \multicolumn{8}{|l|}{ Aging time } \\
\hline & $14 \mathrm{~d}$ & 41.9 & 24.9 & 25.2 & $43.8^{\mathrm{a}}$ & 35.9 & 10.6 \\
\hline & $21 \mathrm{~d}$ & 41.4 & 24.3 & 23.7 & $42.9^{c}$ & 34.4 & 11.3 \\
\hline & $28 \mathrm{~d}$ & 41.3 & 23.5 & 23.5 & $43.6^{\mathrm{ab}}$ & 33.6 & 12.1 \\
\hline & $35 \mathrm{~d}$ & 41.5 & 24.4 & 24.3 & $43.4^{\mathrm{b}}$ & 34.9 & 11.2 \\
\hline & SEM & 0.2 & 0.2 & 0.1 & 0.2 & 0.2 & 0.2 \\
\hline & $P>\mathrm{F}$ & 0.01 & 0.83 & $<0.001$ & $<0.01$ & 0.28 & 0.60 \\
\hline \multicolumn{8}{|l|}{ Marbling class } \\
\hline & Lower Small ${ }^{1}$ & 42.0 & 24.3 & 24.2 & 43.5 & 34.7 & 11.3 \\
\hline & Upper Slight ${ }^{2}$ & 41.1 & 24.3 & 24.2 & 43.4 & 34.7 & 11.3 \\
\hline & SEM & 0.3 & 0.2 & 0.1 & 0.2 & 0.2 & 0.2 \\
\hline & $P>\mathrm{F}$ & 0.02 & 0.89 & 0.73 & 0.88 & 0.99 & 0.85 \\
\hline \multicolumn{8}{|c|}{ Muscle $\times$ aging time interaction } \\
\hline Longissimus lumborum & $14 \mathrm{~d}$ & $41.8^{\mathrm{d}}$ & 29.7 & $26.0^{\mathrm{a}}$ & 38.7 & $39.6^{\mathrm{a}}$ & $5.3^{\mathrm{j}}$ \\
\hline Longissimus lumborum & $21 \mathrm{~d}$ & $41.5^{\mathrm{de}}$ & 29.6 & $25.3^{\mathrm{b}}$ & 37.9 & $39.1^{\mathrm{b}}$ & $6.0^{\mathrm{i}}$ \\
\hline Longissimus lumborum & $28 \mathrm{~d}$ & $41.6^{\mathrm{d}}$ & 29.2 & $24.7^{\mathrm{c}}$ & 37.7 & $38.3^{\mathrm{c}}$ & $6.5^{\mathrm{h}}$ \\
\hline Longissimus lumborum & $35 \mathrm{~d}$ & $41.3^{\mathrm{e}}$ & 28.2 & $24.2^{\mathrm{d}}$ & 38.3 & $37.3^{\mathrm{d}}$ & $7.5^{\mathrm{g}}$ \\
\hline Gluteus medius & $14 \mathrm{~d}$ & $43.3^{\mathrm{a}}$ & 23.9 & $26.1^{\mathrm{a}}$ & 46.0 & $35.9^{\mathrm{e}}$ & $13.5^{\mathrm{e}}$ \\
\hline Gluteus medius & $21 \mathrm{~d}$ & $42.5^{\mathrm{b}}$ & 23.2 & $25.1^{\mathrm{b}}$ & 45.8 & $34.6^{\mathrm{f}}$ & $14.0^{\text {cd }}$ \\
\hline Gluteus medius & $28 \mathrm{~d}$ & $42.1^{\mathrm{c}}$ & 23.1 & $24.3^{\mathrm{d}}$ & 45.1 & $34.0^{\mathrm{g}}$ & $14.0^{\mathrm{c}}$ \\
\hline Gluteus medius & $35 \mathrm{~d}$ & $42.5^{\mathrm{b}}$ & 22.4 & $24.1^{\mathrm{d}}$ & 45.8 & $33.4^{\mathrm{h}}$ & $14.7^{\mathrm{a}}$ \\
\hline Biceps femoris & $14 \mathrm{~d}$ & $40.8^{\mathrm{f}}$ & 21.2 & $23.5^{\mathrm{e}}$ & 46.8 & $32.2^{\mathrm{i}}$ & $13.0^{\mathrm{f}}$ \\
\hline Biceps femoris & $21 \mathrm{~d}$ & $40.1^{\mathrm{g}}$ & 20.5 & $22.5^{\mathrm{f}}$ & 46.5 & $30.9^{\mathrm{j}}$ & $13.7^{\text {cde }}$ \\
\hline Biceps femoris & $28 \mathrm{~d}$ & $40.2^{\mathrm{g}}$ & 20.6 & $22.2^{\mathrm{g}}$ & 46.1 & $30.8^{\mathrm{j}}$ & $13.5^{\mathrm{de}}$ \\
\hline \multirow[t]{3}{*}{ Biceps femoris } & $35 \mathrm{~d}$ & $40.7^{\mathrm{f}}$ & 20.0 & $22.1^{\mathrm{g}}$ & 46.8 & $30.2^{\mathrm{k}}$ & $14.1^{\mathrm{b}}$ \\
\hline & SEM & 0.2 & 0.2 & 0.1 & 0.3 & 0.2 & 0.2 \\
\hline & $P>\mathrm{F}$ & $<0.001$ & 0.16 & $<0.01$ & 0.74 & 0.02 & 0.01 \\
\hline \multicolumn{8}{|c|}{ Muscle $\times$ marbling class interaction } \\
\hline Longissimus lumborum & Lower Small ${ }^{1}$ & $41.9^{\mathrm{c}}$ & $29.0^{\mathrm{a}}$ & $25.0^{\mathrm{ab}}$ & 38.2 & $38.4^{\mathrm{a}}$ & $6.4^{\mathrm{c}}$ \\
\hline Longissimus lumborum & Upper Slight ${ }^{2}$ & $41.2^{\mathrm{d}}$ & $29.4^{\mathrm{a}}$ & $25.1^{\mathrm{a}}$ & 38.0 & $38.7^{\mathrm{a}}$ & $6.2^{\mathrm{c}}$ \\
\hline Gluteus medius & Lower Small ${ }^{1}$ & $43.2^{\mathrm{a}}$ & $23.1^{\mathrm{b}}$ & $24.9^{\mathrm{ab}}$ & 45.7 & $34.4^{\mathrm{b}}$ & $14.2^{\mathrm{a}}$ \\
\hline Gluteus medius & Upper Slight ${ }^{2}$ & $42.0^{\mathrm{b}}$ & $23.2^{\mathrm{b}}$ & $24.9^{\mathrm{b}}$ & 45.6 & $34.5^{\mathrm{b}}$ & $13.8^{\mathrm{ab}}$ \\
\hline Biceps femoris & Lower Small ${ }^{1}$ & $40.8^{\mathrm{e}}$ & $20.7^{\mathrm{c}}$ & $22.7^{\mathrm{c}}$ & 46.5 & $31.2^{\mathrm{c}}$ & $13.3^{\mathrm{b}}$ \\
\hline \multirow[t]{3}{*}{ Biceps femoris } & Upper Slight ${ }^{2}$ & $40.1^{\mathrm{f}}$ & $20.4^{\mathrm{c}}$ & $22.4^{\mathrm{c}}$ & 46.6 & $30.8^{\mathrm{c}}$ & $13.8^{\mathrm{ab}}$ \\
\hline & SEM & 0.3 & 0.3 & 0.1 & 0.3 & 0.2 & 0.3 \\
\hline & $P>\mathrm{F}$ & $<0.01$ & 0.02 & 0.04 & 0.42 & 0.01 & $<0.01$ \\
\hline \multicolumn{8}{|c|}{ Aging time $\times$ marbling class interaction } \\
\hline $14 \mathrm{~d}$ & Lower Small ${ }^{1}$ & $42.5^{\mathrm{a}}$ & $24.7^{\mathrm{ab}}$ & $25.4^{\mathrm{a}}$ & 43.9 & $35.6^{\mathrm{a}}$ & 10.8 \\
\hline $14 \mathrm{~d}$ & Upper Slight $^{2}$ & $41.4^{\mathrm{c}}$ & $25.2^{\mathrm{a}}$ & $25.1^{\mathrm{a}}$ & 43.7 & $36.2^{\mathrm{a}}$ & 10.4 \\
\hline $21 \mathrm{~d}$ & Lower Small ${ }^{1}$ & $41.5^{\mathrm{c}}$ & $24.5^{\mathrm{ab}}$ & $24.4^{\mathrm{b}}$ & 43.4 & $34.9^{\mathrm{b}}$ & 11.2 \\
\hline $21 \mathrm{~d}$ & Upper Slight ${ }^{2}$ & $41.2^{\mathrm{c}}$ & $24.4^{\mathrm{b}}$ & $24.3^{\mathrm{b}}$ & 43.4 & $34.8^{\mathrm{bc}}$ & 11.2 \\
\hline $28 \mathrm{~d}$ & Lower Small ${ }^{1}$ & 42. $0^{\mathrm{b}}$ & $24.2^{\mathrm{b}}$ & $23.8^{\mathrm{c}}$ & 43.0 & $34.3^{\mathrm{cd}}$ & 11.3 \\
\hline $28 \mathrm{~d}$ & Upper Slight ${ }^{2}$ & $40.7^{\mathrm{d}}$ & $24.4^{\mathrm{b}}$ & $23.7^{\mathrm{c}}$ & 42.9 & $34.5^{\text {bcd }}$ & 11.3 \\
\hline
\end{tabular}


Table 1. (Continued)

\begin{tabular}{|c|c|c|c|c|c|c|c|}
\hline Main effects and interactions & & $L^{*}$ & $a^{*}$ & $b^{*}$ & Hue angle & Chroma & $\Delta \mathrm{E}$ \\
\hline $35 \mathrm{~d}$ & Lower Small $^{1}$ & $41.9^{\mathrm{b}}$ & $23.7^{\mathrm{c}}$ & $23.7^{\mathrm{c}}$ & 43.6 & $33.9^{\mathrm{de}}$ & 12.0 \\
\hline \multirow{3}{*}{$35 \mathrm{~d}$} & Upper Slight $^{2}$ & $41.1^{\mathrm{c}}$ & $23.3^{\mathrm{c}}$ & $23.2^{\mathrm{d}}$ & 43.7 & $33.3^{\mathrm{e}}$ & 12.2 \\
\hline & SEM & 0.3 & 0.3 & 0.1 & 0.3 & 0.3 & 0.3 \\
\hline & $P>\mathrm{F}$ & $<0.001$ & 0.04 & $<0.01$ & 0.89 & $<0.01$ & 0.53 \\
\hline
\end{tabular}

than in either biceps femoris or gluteus medius steaks at all aging times. Generally, increasing aging time increased $(P<0.05)$ the amount of color change observed in all muscles, although this trend was more pronounced in longissimus lumborum steaks than in gluteus medius or biceps femoris steaks.

Muscle and marbling class interacted to affect $L^{*}$, $a^{*}, b^{*}$, chroma, and overall color change $(\Delta \mathrm{E})$. Steaks from carcasses with Lower Small marbling had higher $(P<0.05) L^{*}$ values than those from carcasses with Upper Slight marbling regardless of muscle, but the magnitude of the differences was greater for gluteus medius. Values for $a^{*}$ were highest $(P<0.05)$ in longissimus lumborum steaks, intermediate in gluteus medius steaks, and lowest $(P<0.05)$ in biceps femoris steaks. Longissimus lumborum steaks from carcasses with Upper Slight marbling scores had higher $(P<0.02)$ $b^{*}$ values than gluteus medius steaks from carcasses with Upper Slight marbling. Longissimus lumborum and gluteus medius steaks from carcasses with Lower Small marbling scores did not differ $(P=0.50)$ in $b^{*}$ values. Longissimus lumborum steaks exhibited much less $(P<0.05)$ overall color change than gluteus medius or biceps femoris steaks. Within muscle, marbling class differences in color change were not significant, but color change was greater $(P<0.001)$ in gluteus medius steaks from carcasses with Lower Small marbling than in biceps femoris steaks from carcasses with Lower Small marbling. Gluteus medius steaks from carcasses with Upper Slight marbling scores did not differ $(P=$ 0.80 ) from biceps femoris steaks from carcasses with Upper Slight marbling scores.

Aging time and marbling class interacted to affect $L^{*}, a^{*}, b^{*}$, and chroma values. Steaks from Lower Small carcasses had higher $(P<0.01) L^{*}$ values than steaks from Upper Slight carcasses at 14, 28, and $35 \mathrm{~d}$ postmortem. In steaks from Upper Slight carcasses, $L^{*}$ values were lower $(P<0.01)$ in steaks aged for $28 \mathrm{~d}$ than steaks subjected to other aging times. However, in steaks from Lower Small carcasses, $L^{*}$ values were highest $(P<0.001)$ when aged for $14 \mathrm{~d}$ compared to all other aging times. As aging time increased, $a^{*}$ values tended to decrease $(P<0.05)$, and $a^{*}$ values did not differ between marbling classes at any of the aging times evaluated in the present experiment. Similar trends were observed for $b^{*}$ and chroma values.

\section{Biochemical traits influencing color stability}

Myoglobin concentration was higher $(P<0.05)$ in biceps femoris steaks than in gluteus medius steaks, followed by longissimus lumborum steaks (Table 2). Muscle $\mathrm{pH}$ was higher in biceps femoris steaks than in gluteus medius or longissimus lumborum steaks. However, this difference in muscle $\mathrm{pH}$ was so small as to have little importance.

Myoglobin concentration increased linearly $(P<$ $0.01)$ with increased aging time although the magnitude of the differences was small (Table 2). This effect could possibly be attributable to moisture losses during aging; however, because purge losses were not measured in the present experiment, this hypothesis cannot be tested. Trends associated with changes in $\mathrm{pH}$ during extended aging time were cubic in nature; however, these differences were small, and the mechanism responsible for these changes is not clear. The relationship between oxygen consumption and aging time in longissimus lumborum was quadratic $(P=0.02)$ in nature, with oxygen consumption decreasing substantially between day 14 and day 21 and then remaining relatively constant through $35 \mathrm{~d}$ of aging.

Nitric oxide metmyoglobin reducing activity decreased dramatically between day 14 and 21, was flat between day 21 and 28, and then decreased slightly between day 28 and 35. Polynomial contrasts indicate that IMF changed cubically $(P<0.001)$ with extended postmortem aging, although these differences were very small. IMF decreased slightly between day 14 and 21 of aging, increased slightly between day 21 and day 28 of aging, and then decreased between day 28 and day 35 of aging. Thus, results pertaining to IMF, which indicate a slight increase in reducing capacity 
Table 2. Least-squares means for biochemical traits for muscle, aging time, and marbling class effects

\begin{tabular}{|c|c|c|c|c|c|}
\hline Main effects & $\begin{array}{c}\text { Myoglobin } \\
\text { concentration, } \mathrm{mg} / \mathrm{mL}\end{array}$ & $\mathrm{pH}$ & $\begin{array}{c}\text { Oxygen } \\
\text { consumption, } \%\end{array}$ & $\begin{array}{l}\text { Nitric oxide metmyoglobin } \\
\text { reducing ability, } \%\end{array}$ & $\begin{array}{l}\text { Initial metmyoglobin } \\
\text { formation, } \%\end{array}$ \\
\hline \multicolumn{6}{|l|}{ Muscle } \\
\hline Longissimus lumborum & $4.3^{\mathrm{c}}$ & $5.6^{\mathrm{b}}$ & - & - & - \\
\hline Gluteus medius & $5.3^{\mathrm{b}}$ & $5.6^{\mathrm{b}}$ & - & - & - \\
\hline Biceps femoris & $5.8^{\mathrm{a}}$ & $5.6^{\mathrm{a}}$ & - & - & - \\
\hline SEM & 0.1 & 0.02 & - & - & - \\
\hline$P>\mathrm{F}$ & $<0.001$ & $<0.001$ & - & - & - \\
\hline \multicolumn{6}{|l|}{ Aging } \\
\hline $14 \mathrm{~d}$ & 5.0 & 5.6 & 59.1 & 72.0 & 81.4 \\
\hline $21 \mathrm{~d}$ & 5.1 & 5.6 & 53.2 & 57.6 & 78.7 \\
\hline $28 \mathrm{~d}$ & 5.2 & 5.6 & 50.5 & 57.5 & 80.6 \\
\hline $35 \mathrm{~d}$ & 5.3 & 5.5 & 53.9 & 53.7 & 76.1 \\
\hline SEM & 0.1 & 0.02 & 2.5 & 2.7 & 3.3 \\
\hline$P>\mathrm{F}$ & $<0.01$ & $<0.001$ & 0.02 & $<0.001$ & $<0.001$ \\
\hline Linear $P>\mathrm{F}$ & $<0.01$ & $<0.001$ & 0.04 & $<0.001$ & 0.03 \\
\hline Quadratic $P>\mathrm{F}$ & 0.94 & $<0.001$ & 0.02 & 0.00 & 0.03 \\
\hline Cubic $P>\mathrm{F}$ & 0.86 & $<0.001$ & 0.75 & 0.02 & $<0.001$ \\
\hline \multicolumn{6}{|l|}{ Marbling class } \\
\hline Lower Small $^{1}$ & 5.1 & 5.6 & 51.7 & 59.1 & 79.2 \\
\hline Upper Slight ${ }^{2}$ & 5.1 & 5.6 & 56.7 & 61.3 & 79.2 \\
\hline SEM & 0.1 & 0.0 & 2.1 & 2.4 & 3.3 \\
\hline$P>\mathrm{F}$ & 0.87 & 0.58 & 0.03 & 0.19 & 0.87 \\
\hline
\end{tabular}

with postmortem aging, are in contrast with results pertaining to nitric oxide metmyoglobin reducing ability, which indicate a substantial loss in reducing capacity with postmortem aging. Of the component traits, only oxygen consumption was affected by marbling class. Oxygen consumption was greater $(P<0.03)$ in steaks from carcasses with marbling scores in the Upper Slight class than in those from the Lower Small class.

\section{Correlations between biochemical factors and color attributes of longissimus lumborum}

To allow insight into the contribution of each of the component traits to variation in lean color stability, as well as to the aging effect, correlation coefficients were calculated both for relationships among the raw data and residuals of a mixed model accounting for aging time effects in these traits (Table 3). Increased myoglobin concentration was associated with darker lean color (lower $L^{*}$ values; $P<0.05$ ) on day 0 and 11 of display and greater red lean color (higher $a^{*}$ and lower hue angle values; $P<0.05)$ on day 0 of display. Increased myoglobin concentration was also associated with increased color change $(P<0.05)$ during simulated retail display. When postmortem aging effects were removed from the dataset, these relationships remained, except that day 0 hue angle values were no longer significantly $(P>0.05)$ correlated to myoglobin concentration.

A relationship $(P<0.05)$ existed between day 0 hue angle values and muscle $\mathrm{pH}$, and this relationship remained $(P<0.05)$ when aging effects were removed. Moreover, when aging effects were removed, increased muscle $\mathrm{pH}$ was moderately related $(P<0.05)$ to less redness and increased color change on day 11 of simulated retail display $(P<0.05)$. Increased oxygen consumption was associated with darker lean color $(P<$ 0.05 ) on day 0 and 11 of simulated retail display. After removing aging effects, oxygen consumption was still correlated to day 0 and $11 L^{*}$ values $(P<0.05)$ and was related to increased color change during simulated retail display $(P<0.05)$. At the start of simulated retail display, increased nitric oxide metmyoglobin reducing ability was associated with darker (lower $L^{*} ; P<0.05$ ) and less red (higher hue angle values; $P<0.05$ ) lean color. At the end of simulated retail display, increased nitric oxide metmyoglobin reducing ability 
Table 3. Pearson correlation coefficients between biochemical traits and color attributes of longissimus lumborum steaks on day 0 or 11 of simulated retail display

\begin{tabular}{|c|c|c|c|c|c|}
\hline Trait & $\begin{array}{c}\text { Myoglobin } \\
\text { concentration }\end{array}$ & $\mathrm{pH}$ & $\begin{array}{c}\text { Oxygen } \\
\text { consumption }\end{array}$ & $\begin{array}{l}\text { Nitric oxide metmyoglobin } \\
\text { reducing ability }\end{array}$ & $\begin{array}{c}\text { Initial metmyoglobin } \\
\text { formation }\end{array}$ \\
\hline \multicolumn{6}{|l|}{ Correlations of raw data } \\
\hline Day $0 L^{*}$ & $-0.38^{\mathrm{a}}$ & 0.03 & $-0.33^{\mathrm{a}}$ & $-0.18^{\mathrm{a}}$ & $0.34^{\mathrm{a}}$ \\
\hline Day $0 a^{*}$ & $0.22^{\mathrm{a}}$ & 0.09 & -0.05 & -0.06 & -0.06 \\
\hline Day 0 hue angle & $-0.14^{\mathrm{a}}$ & $-0.18^{\mathrm{a}}$ & -0.06 & $0.20^{\mathrm{a}}$ & -0.06 \\
\hline Day $11 L^{*}$ & $-0.41^{\mathrm{a}}$ & 0.10 & $-0.26^{\mathrm{a}}$ & 0.02 & $0.38^{\mathrm{a}}$ \\
\hline Day $11 a^{*}$ & -0.13 & -0.03 & -0.04 & $0.19^{\mathrm{a}}$ & 0.01 \\
\hline Day 11 hue angle & 0.12 & 0.11 & 0.04 & -0.09 & 0.07 \\
\hline Day 11 overall color change & $0.18^{\mathrm{a}}$ & 0.01 & 0.03 & $-0.20^{\mathrm{a}}$ & -0.06 \\
\hline \multicolumn{6}{|c|}{ Correlations of residuals after aging effects were removed ${ }^{1}$} \\
\hline Day $0 L^{*}$ & $-0.21^{\mathrm{a}}$ & -0.09 & $-0.25^{\mathrm{a}}$ & $-0.14^{\mathrm{a}}$ & $0.21^{\mathrm{a}}$ \\
\hline Day $0 a^{*}$ & $0.22^{\mathrm{a}}$ & 0.12 & 0.08 & 0.08 & -0.04 \\
\hline Day 0 hue angle & -0.10 & $-0.17^{\mathrm{a}}$ & -0.04 & $0.30^{\mathrm{a}}$ & $0.14^{\mathrm{a}}$ \\
\hline Day $11 L^{*}$ & $-0.26^{\mathrm{a}}$ & -0.06 & $-0.19^{\mathrm{a}}$ & -0.04 & $0.21^{\mathrm{a}}$ \\
\hline Day $11 a^{*}$ & -0.10 & $-0.17^{\mathrm{a}}$ & -0.12 & $0.15^{\mathrm{a}}$ & 0.05 \\
\hline Day 11 hue angle & 0.04 & $0.21^{\mathrm{a}}$ & 0.04 & $-0.19^{\mathrm{a}}$ & 0.08 \\
\hline Day 11 overall color change & $0.17^{\mathrm{a}}$ & $0.18^{\mathrm{a}}$ & $0.19^{\mathrm{a}}$ & -0.05 & -0.11 \\
\hline
\end{tabular}

${ }^{1}$ Correlations among residual values from a mixed model accounting for the fixed effect of aging time.

${ }^{\mathrm{a} P}<0.05$.

was associated with greater redness (higher $a^{*}$ values; $P<0.05)$ and less overall color change $(P<0.05)$. When aging effects were removed, increased nitric oxide metmyoglobin reducing ability had similar associations. Increased IMF was associated $(P<0.05)$ with increased $L^{*}$ values on day 0 and 11 of simulated retail display. When aging effects were removed, IMF was associated $(P<0.05)$ with lighter and less red lean.

\section{Discussion}

\section{Color stability differed across muscles}

The 3 muscles evaluated in the present experiment differed regarding lean color stability. Color attributes were much more stable during simulated retail display in longissimus lumborum steaks than in gluteus medius or biceps femoris steaks. Changes in color attributes during simulated retail display were generally less extensive in gluteus medius steaks than in biceps femoris steaks, although the magnitude of these differences was generally small. In our previous comparison of 14 beef muscles (King et al., 2011), the longissimus lumborum was the most stable, the sirloin cap portion of the biceps femoris was the least stable, and the gluteus medius was intermediate with regard to lean color stability. These differences in lean color stability across muscles are consistent with other comparisons of beef muscles (Faustman and Cassens, 1991; Lanari and Cassens, 1991; McKenna et al., 2005). Muscle metabolism may play a role in muscle differences in color stability. Myoglobin concentration is an indicator of oxidative capacity of a muscle. In this experiment, ranking these muscles for myoglobin concentration was inverse to their rankings for color stability. In agreement with the present experiment, Hunt and Hedrick (1977) reported that gluteus medius steaks had greater myoglobin concentration than longissimus lumborum steaks.

Kirchofer et al. (2002) classified each of the muscles studied in the present experiment as "White" based on muscle fiber type. Joo et al. (2017) found gluteus medius muscles to have a greater proportion of type IIB fibers and a lower proportion of type IIA fibers than longissimus lumborum muscles. In contrast, Hunt and Hedrick (1977) reported a greater proportion of $\alpha$ - White fibers in longissimus lumborum muscles compared to gluteus medius. Proteomic studies of muscles differing in color stability found muscles with stable lean color to have greater abundance of glycolytic enzymes (Joseph et al., 2012; Nair et al., 2018). Moreover, color-stable muscles had greater abundance of proteins that function as antioxidants and chaperones that protect other proteins from denaturation and aggregation during the conversion of muscle to meat (Joseph et al., 2012). Nair et al. (2018) suggested that the greater abundance of glycolytic enzymes may enable 
the generation of reduced nicotinamide adenine dinucleotide, which is needed for metmyoglobin reduction.

\section{Extended postmortem aging affected color stability}

Postmortem aging varies widely across the industry, with product available at retail outlets after aging times from 6 to $101 \mathrm{~d}$ postmortem (Martinez et al., 2017). Postmortem aging has been reported to affect the biochemical processes determining lean color stability (Ledward, 1985; Feldhusen et al., 1995; Tang et al., 2005a). The shapes of regression curves describing the changes in color attributes of these steaks during display in the current experiment indicate that the prolonged aging time decreased lean color stability in these muscles. Liu et al. (1996) reported that increasing aging time of longissimus lumborum steaks from 14 to 28 and from 28 to $56 \mathrm{~d}$ postmortem increased changes in $a^{*}$ and hue angle values. This is consistent with aging effects that were previously reported (Mancini and Ramanathan, 2014; Nair et al., 2014; English et al., 2016; Mitacek et al., 2019). The results of the present experiment were in partial agreement with those of Lindahl (2011), who reported that longissimus lumborum and semimembranosus steaks aged in vacuum for $5 \mathrm{~d}$ had less surface metmyoglobin formation during $5 \mathrm{~d}$ of aerobic dark storage than steaks of the same muscles aged for $25 \mathrm{~d}$ in vacuum. However, Lindahl (2011) also reported steaks that were not aged ( $2 \mathrm{~d}$ postmortem) had greater surface metmyoglobin accumulation than steaks that were aged.

In the present experiment, increasing aging time from 14 to $21 \mathrm{~d}$ decreased oxygen consumption and nitric oxide metmyoglobin reducing ability, but further aging had little effect on these traits. In contrast, Mancini and Ramanathan (2014) reported progressive decreases in mitochondrial oxygen consumption and metmyoglobin reducing activity with increased postmortem aging up to $45 \mathrm{~d}$ postmortem. English et al. (2016) reported progressive decreases in nitric oxide reducing activity in longissimus lumborum steaks with increased aging from 21 to $62 \mathrm{~d}$ postmortem. Those investigators detected decreases in oxygen consumption between 21 and $42 \mathrm{~d}$ postmortem but did not detect a difference in oxygen consumption when aging time was increased from 42 to $62 \mathrm{~d}$ postmortem. Nair et al. (2018) also reported decreased metmyoglobin reducing ability and, consequently, reduced redness of beef muscles with increased aging times up to $21 \mathrm{~d}$. Those investigators also indicated that glycolytic enzymes were more abundant in muscles at aging times with greater color stability and may indicate the availability of substrates needed for metmyoglobin reduction. This finding is supported by the report of depletion of metabolites that can regenerate nicotinamide adenine dinucleotide with increased aging time of beef longissimus lumborum steaks (Mitacek et al., 2019).

\section{Marbling class had little effect on color stability}

The marbling classes studied in the present experiment reflect a large difference in carcass values (U.S. Choice vs. U.S. Select). However, the actual difference in marbling is small. Thus, the finding that the marbling classes in the present experiment had little impact on the color stability traits evaluated was not entirely unexpected. Larger marbling differences are likely to represent histochemical differences in the muscle that warrant further investigation.

The findings of the present experiment are in contrast with the reports of Behrends et al. (2003), which indicated that round muscles of U.S. Low Choice carcasses had less surface discoloration during $10 \mathrm{~d}$ of simulated retail display than those from U.S. High Choice or Select carcasses. Correale et al. (1986) reported that longissimus lumborum steaks from U.S. Prime carcasses had less surface discoloration after $6 \mathrm{~d}$ of simulated retail display than longissimus lumborum steaks from U.S. Good (now U.S. Select) carcasses. It should be noted that both Correale et al. (1986) and Behrends et al. (2003) used very small sample sizes ( $n=5$ and 3 carcasses per grade group, respectively) such that a single carcass with divergent color stability properties could have skewed the grade group mean. King et al. (2011) reported that quality grade (U.S. Choice vs. U.S. Select; i.e. marbling groups similar to those reported in the present experiment) had negligible contribution to the variance in color attributes during simulated retail display.

\section{Conclusions}

From these results, it is evident that the longissimus lumborum was the most color-stable muscle evaluated in the present experiment. Color stability was similar between the biceps femoris and gluteus medius steaks. Increasing aging time generally reduced lean color stability, although these differences were not as extensive as expected and were muscle dependent. Marbling score had little effect on color stability. 


\section{Acknowledgments}

This project was funded, in part, by the Beef Checkoff. Mention of trade names or commercial products in this publication is solely for the purpose of providing specific information and does not imply recommendation or endorsement by the US Department of Agriculture. The authors are grateful to Patty Beska, Kristen Ostdiek, Kathy Mihm, and Pat Tammen of the US Meat Animal Research Center for their assistance in the execution of this experiment and to Jody Gallagher of the US Meat Animal Research Center for her secretarial assistance. The USDA is an equal opportunity provider and employer.

\section{Literature Cited}

American Meat Science Association (Editor). 2012. AMSA Meat Color Measurement Guidelines. In: AMSA Meat Color Measurement Guidelines. Am. Meat Sci. Assoc. Champaign, IL. p. 80 .

Behrends, J. M., W. B. Mikel, C. L. Armstrong, and M. C. Newman. 2003. Color stability of semitendinosus, semimembranosus, and biceps femoris steaks packaged in a highoxygen modified atmosphere. J. Anim. Sci. 81:2230-2238. https://doi.org/10.2527/2003.8192230x.

Bendall, J. R. 1973. In: G. H., Bourne editor, The structure and function of muscle. Vol. 2. Academic Press, New York. p. 243.

Boleman, S. J., S. L. Boleman, R. K. Miller, J. F. Taylor, H. R. Cross, T. L. Wheeler, M. Koohmaraie, S. D. Shackelford, M. F. Miller, R. L. West, D. D. Johnson, and J. W. Savell. 1997. Consumer evaluation of beef of known categories of tenderness. J. Anim. Sci. 75:1521-1524. https://doi.org/10. 2527/1997.7561521x.

Colle, M. J., R. P. Richard, K. M. Killinger, J. C. Bohlscheid, A. R. Gray, W. I. Loucks, R. N. Day, A. S. Cochran, J. A. Nasados, and M. E. Doumit. 2015. Influence of extended aging on beef quality characteristics and sensory perception of steaks from the gluteus medius and longissimus lumborum. Meat Sci. 110:32-39. https://doi.org/10.1016/j.meatsci.2015.06.013.

Correale, K. K., J. W. Savell, D. B. Griffin, G. R. Acuff, and C. Vanderzant. 1986. Microbiological and sensory characteristics of beef loin steaks: Role of intramuscular fat. Meat Sci. 18:161-172. https://doi.org/10.1016/0309-1740(86) 90030-6.

English, A. R., G. G. Mafi, D. L. VanOverbeke, and R. Ramanathan. 2016. Effects of extended aging and modified atmospheric packaging on beef top loin steak color. J. Anim. Sci. 94:1727-1737. https://doi.org/10.2527/jas.2015-0149.

Faustman, C., and R. G. Cassens. 1991. The effect of cattle breed and muscle type on discoloration and various biochemical parameters in fresh beef. J. Anim. Sci. 69:184-193.

Feldhusen, F., A. Warnatz, R. Erdmann, and S. Wenzel. 1995. Influence of storage time on parameters of colour stability of beef. Meat Sci. 40:235-243. https://doi.org/10.1016/ 0309-1740(94)00048-c.
Gruber, S. L., J. D. Tatum, J. A. Scanga, P. L. Chapman, G. C. Smith, and K. E. Belk. 2006. Effects of postmortem aging and USDA quality grade on Warner-Bratzler shear force values of seventeen individual beef muscles. J. Anim. Sci. 84:3387-3396. https://doi.org/10.2527/jas.2006-194.

Hunt, M. C., and H. B. Hedrick. 1977. Profile of fiber types and related properties of five bovine muscles. J. Food Sci. 42:513-517. https://doi.org/10.1111/j.1365-2621.1977.tb01535.x.

Hunt, M. C., O. Sørheim, and E. Slinde. 1999. Color and heat denaturation of myoglobin forms in ground beef. J. Food. Sci. 64:847851. https://doi.org/10.1111/j.1365-2621.1999.tb15925.x.

Joo, S.-H., K.-W. Lee, Y.-H. Hwang, and S.-T. Joo. 2017. Histochemical characteristics in relation to meat quality traits of eight major muscles from Hanwoo steers. Korean J. Food Sci. An. 37:716-725. https://doi.org/10.5851/kosfa.2017.37. 5.716.

Joseph, P., S. P. Suman, G. Rentfrow, S. Li, and C. M. Beach. 2012. Proteomics of muscle-specific beef color stability. J. Agr. Food Chem. 60:3196-3203. https://doi.org/10.1021/jf204188v.

King, D. A., S. D. Shackelford, and T. L. Wheeler. 2011. Relative contributions of animal and muscle effects to variation in beef lean color stability. J. Anim. Sci. 89:1434-1451. https://doi. org/10.2527/jas.2010-3595.

King, D. A., S. D. Shackelford, T. L. Wheeler, K. D. Pfeiffer, J. M. Mehaffey, M. F. Miller, R. Nickelson, and M. Koohmaraie. 2009a. Consumer acceptance and steak cutting yields of beef top sirloin and knuckle subprimals. Meat Sci. 83:782-787. https://doi.org/10.1016/j.meatsci.2009.08.021.

King, D. A., T. L. Wheeler, S. D. Shackelford, and M. Koohmaraie. 2009b. Comparison of palatability characteristics of beef gluteus medius and triceps brachii muscles. J. Anim. Sci. 87:275284. https://doi.org/10.2527/jas.2007-0809.

King, D. A., T. L. Wheeler, S. D. Shackelford, K. D. Pfeiffer, R. Nickelson, and M. Koohmaraie. 2009c. Effect of blade tenderization, aging time, and aging temperature on tenderness of beef longissimus lumborum and gluteus medius. J. Anim. Sci. 87:2952-2960. https://doi.org/10.2527/jas.2009-1803.

Kirchofer, K. S., C. R. Calkins, and B. L. Gwartney. 2002. Fibertype composition of muscles of the beef chuck and round. J. Anim. Sci. 80:2872-2878. https://doi.org/10.2527/2002. 80112872x.

Lanari, M. C., and R. G. Cassens. 1991. Mitochondrial activity and beef muscle color stability. J. Food. Sci. 56:1476-1479. https://doi.org/10.1111/j.1365-2621.1991.tb08619.x.

Ledward, D. A. 1985. Post-slaughter influences on the formation of metyyoglobin in beef muscles. Meat Sci. 15:149-171. https:// doi.org/10.1016/0309-1740(85)90034-8.

Lee, M. S., J. K. Apple, J. W. Yancey, J. T. Sawyer, and Z. B. Johnson. 2008a. Influence of vacuum-aging period on bloom development of the beef gluteus medius from top sirloin butts. Meat Sci. 80:592-598. https://doi.org/10.1016/j.meatsci. 2008.02.006.

Lee, M. S., J. K. Apple, J. W. Yancey, J. T. Sawyer, and Z. B. Johnson. 2008b. Influence of wet-aging on bloom development in the longissimus thoracis. Meat Sci. 80:703-707. https://doi.org/10.1016/j.meatsci.2008.03.013.

Lindahl, G. 2011. Colour stability of steaks from large beef cuts aged under vacuum or high oxygen modified atmosphere. 
Meat Sci. 87:428-435. https://doi.org/10.1016/j.meatsci.2010. 10.023

Liu, Q., K. K. Scheller, S. C. Arp, D. M. Schaefer, and M. Frigg. 1996. Color coordinates for assessment of dietary vitamin $\mathrm{E}$ effects on beef color stability. J. Anim. Sci. 74:106-116.

Mancini, R. A., and R. Ramanathan. 2014. Effects of postmortem storage time on color and mitochondria in beef. Meat Sci. 98:65-70. https://doi.org/10.1016/j.meatsci.2014.04.007.

Mancini, R. A., M. C. Hunt, and D. H. Kropf. 2003. Reflectance at 610 nanometers estimates oxymyoglobin content on the surface of ground beef. Meat Sci. 64:157-162. https://doi.org/10. 1016/S0309-1740(02)00174-2.

Martinez, H. A., A. N. Arnold, J. C. Brooks, C. C. Carr, K. B. Gehring, D. B. Griffin, D. S. Hale, G. G. Mafi, D. D. Johnson, C. L. Lorenzen, R. J. Maddock, R. K. Miller, D. L. VanOverbeke, B. E. Wasser, and J. W. Savell. 2017. National beef tenderness survey-2015: Palatability and shear force assessments of retail and foodservice beef. Meat Muscle Biol. 1:138-148. https://doi.org/10.22175/mmb2017.05.0028.

McKenna, D. R., P. D. Mies, B. E. Baird, K. D. Pfeiffer, J. W. Ellebracht, and J. W. Savell. 2005. Biochemical and physical factors affecting discoloration characteristics of 19 bovine muscles. Meat Sci. 70:665-682. https://doi.org/10.1016/j. meatsci.2005.02.016.

Miller, M. F., M. A. Carr, C. B. Ramsey, K. L.* Crockett, and L. C. Hoover. 2001. Consumer thresholds for establishing the value of beef tenderness. J. Anim. Sci. 79:3062-3068. https://doi. org/10.2527/2001.79123062x.

Mitacek, R. M., Y. Ke, J. E. Prenni, R. Jadeja, D. L. VanOverbeke, G. G. Mafi, and R. Ramanathan. 2019. Mitochondrial degeneration, depletion of $\mathrm{NADH}$, and oxidative stress decrease color stability of wet-aged beef longissimus steaks. J. Food Sci. 84:38-50. https://doi.org/10.1111/1750-3841.14396.

Nair, M. N., S. Li, C. M. Beach, G. Rentfrow, and S. P. Suman. 2018. Changes in the sarcoplasmic proteome of beef muscles with differential color stability during postmortem aging. Meat Muscle Biol. 2:1-17. https://doi.org/10.22175/mmb2017. 07.0037.

Nair, M. N., S. P. Suman, S. Li, P. Joseph, and C. M. Beach. 2014. Lipid oxidation-induced oxidation in emu and ostrich myoglobins. Meat Sci. 96:984-993. https://doi.org/10.1016/j. meatsci.2013.08.029.
Neely, T. R., C. L. Lorenzen, R. K. Miller, J. D. Tatum, J. W. Wise, J. F. Taylor, M. J. Buyck, J. O. Reagan, and J. W. Savell. 1998. Beef customer satisfaction: role of cut, USDA quality grade, and city on in-home consumer ratings. J. Anim. Sci. 76:1027-1033. https://doi.org/10.2527/1998. 7641027x.

Ramanathan, R., R. A. Mancini, P. Joseph, and S. P. Suman. 2013. Bovine mitochondrial oxygen consumption effects on oxymyoglobin in the presence of lactate as a substrate for respiration. Meat Sci. 93:893-897. https://doi.org/10.1016/j. meatsci.2012.12.005.

Sammel, L. M., M. C. Hunt, D. H. Kropf, K. A. Hachmeister, and D. E. Johnson. 2002. Comparison of assays for metmyoglobin reducing ability in beef inside and outside semimembranosus muscle. J. Food Sci. 67:978-984. https://doi.org/10.1111/j. 1365-2621.2002.tb09439.x.

Shackelford, S. D., T. L. Wheeler, and M. Koohmaraie. 2003. Online prediction of yield grade, longissimus muscle area, preliminary yield grade, adjusted preliminary yield grade, and marbling score using the MARC beef carcass image analysis system. J. Anim. Sci. 81:150-155. https://doi.org/10.2527/ 2003.811150x.

Shackelford, S. D., T. L. Wheeler, M. K. Meade, J. O. Reagan, B. L. Byrnes, and M. Koohmaraie. 2001. Consumer impressions of Tender Select beef. J. Anim. Sci. 79:2605-2614. https://doi. org/10.2527/2001.79102605x.

Tang, J., C. Faustman, T. A. Hoagland, R. A. Mancini, M. Seyfert, and M. C. Hunt. 2005a. Postmortem oxygen consumption by mitochondria and its effects on myoglobin form and stability. J. Agr. Food Chem. 53:1223-1230. https://doi.org/10.1021/ jf048646o.

Tang, J., C. Faustman, R. A. Mancini, M. Seyfert, and M. C. Hunt. 2005b. Mitochondrial reduction of metmyoglobin: Dependence on the electron transport chain. J. Agr. Food Chem. 53:5449-5455. https://doi.org/10.1021/jf050092h.

USDA. 2014. Institutional Meat Purchase Specifications Fresh Beef Series 100. https://www.ams.usda.gov/sites/default/files/ media/IMPS_100_Fresh_Beef\%5B1\%5D.pdf. (Accessed 3 May 2018.)

Warris, P. D. 1979. The extraction of haem pigments from fresh meat. Int. J. Food Sci. Tech. 14:75-80. https://doi.org/10. 1111/j.1365-2621.1979.tb00849.x. 